$$
\text { التقابل بين اللغتين العربية و الإندونيسية }
$$

\title{
Turkis Lubis
}

\author{
Pascasarjana UIN Maliki Malang
}

Email. torkislubis@yahoo.com

\begin{abstract}
This is a plain contrastive descriptive study between two languages, Arabic and Indonesian, especially the contrast between their phonetics, lexical, phonological and syntax levels. The research concludes within that there is similarity and differentiation in its phonetics, lexical, phonological and syntax systems. In phonetics we found a contrast related to consonants and vocals sounds, and also in syllable sounds. In lexical domain, there is a meaning formulated in one word in Arabic language, but in Indonesian language we found it composed of two words, for example: مستثفى وغداء وعثاء وغيرها, rumah sakit, makan siang, makan malam and others. In the phonology, it is found out that Arabic language is an etymological language and the Indonesian language is an affix language, and Arabic language adopt systems of masculine, feminine, singular, dual (mutsanna) and plural which is different from Indonesian language. In syntax of Indonesian language, we found that the meaning is defined by the combination of the words and its position, it is based on subject combination (nominal clause), in other hand we found that the Arabic language is a syntax language (lughah mu'rabah), the meaning is defined by the syntax (al i'rab) and it adopts both of nominal clause and verbal clause. Those Arabic phenomena which are not adopted by Indonesian language should be taken into account in learning and teaching Arabic Language by the Indonesians.
\end{abstract}

\section{Keywords}

Contrastive Descriptive, Arabic Language And Indonesian Language

مقدمة

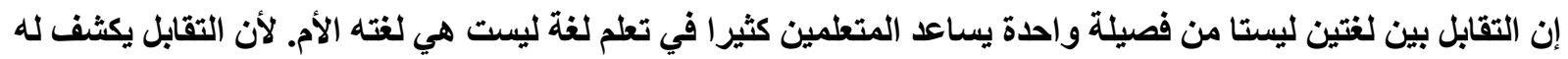

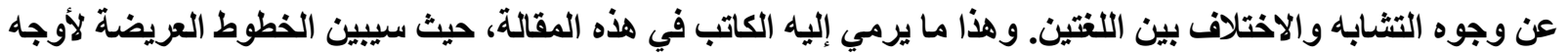

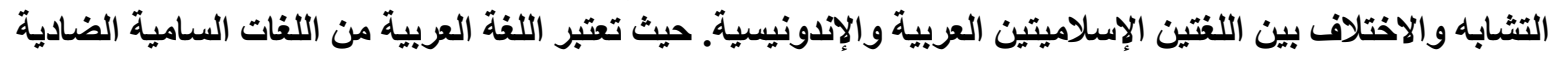

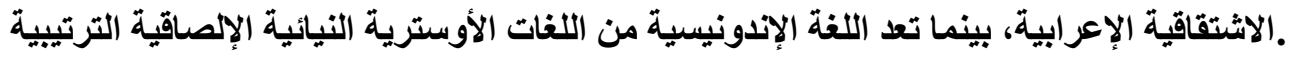

$$
\begin{aligned}
& \text { التقابل اللغوي: معناه وتاريخه }
\end{aligned}
$$

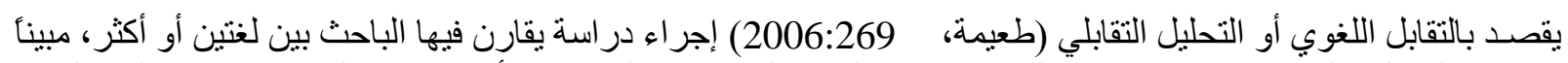

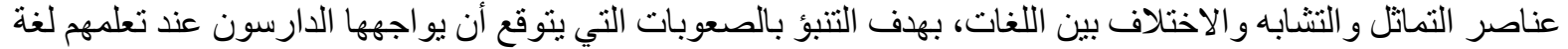

$$
\begin{aligned}
& \text { أجنبية. و هذا بالتالي يساعد في عدة أمور ؛ منها : تأليف الكتب و المو اد التعليمية المناسبة، و إعداد الاختبار التئ التئ اللغوية المناسبة } \\
& \text { أيضأ و غير ذللك من المجالات العملية التعليمية. }
\end{aligned}
$$

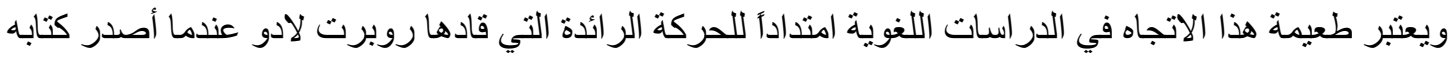

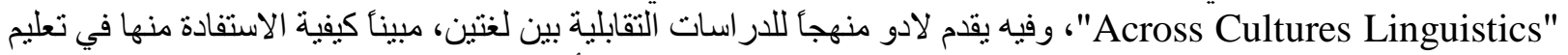

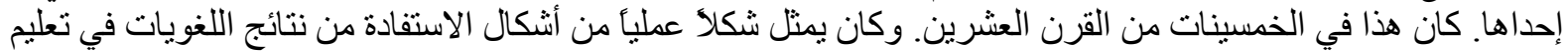




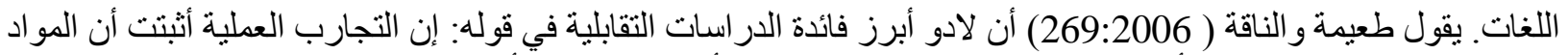

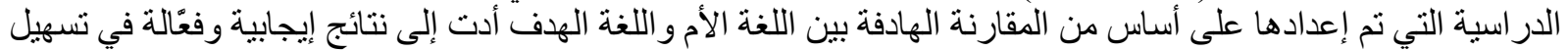

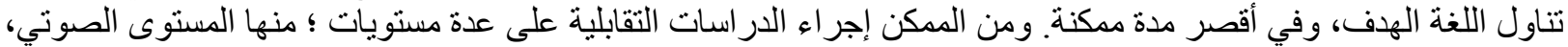
و المستوى النحوي، والمستوى التركيبي، و المستوى الصرفي، والتوني، المستوى الدلالي، و المستوى الثقافي. وكان هذا التقابل المبسط

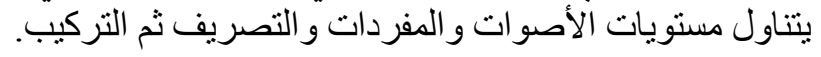

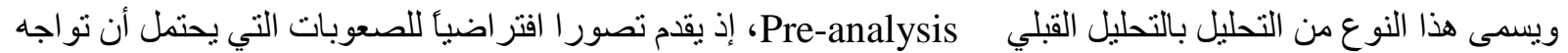

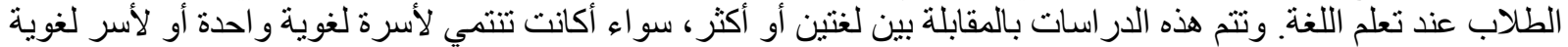

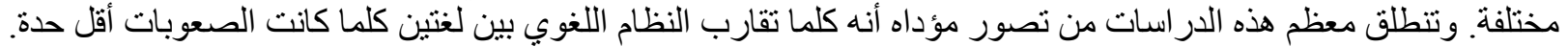

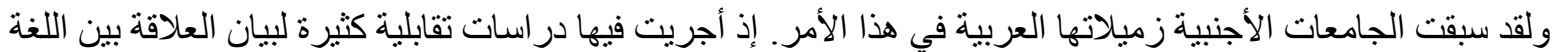

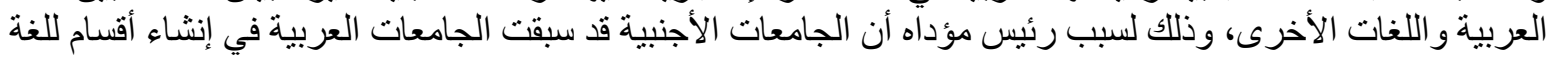
العربية، ينتظم فيها طلاب غير عرب، مما استلزم إجر اء در اسات تقابلية يسهم الباحثون فيها في تسهيل تعليم العربية في هذه الإن البلاد الأجنبية.

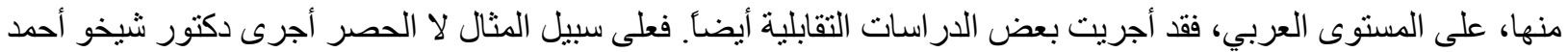

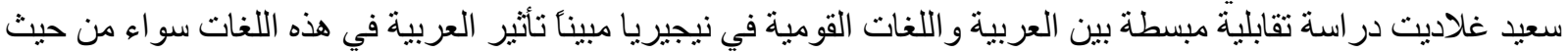
الأصوات أو المفردات أو الترابلة اكبيب.

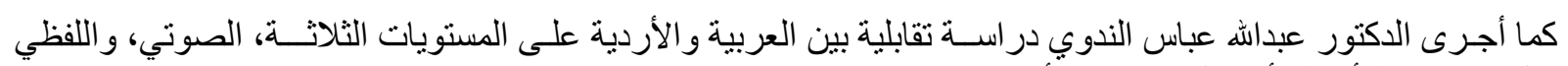

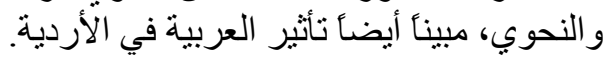

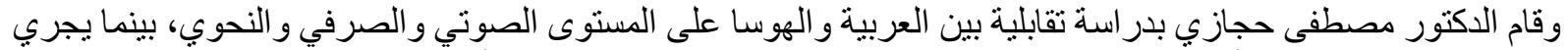

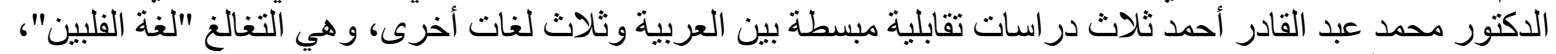
و البشتو "لغة أفغانستان"، و السور السوسو لغة درانة غينيا.

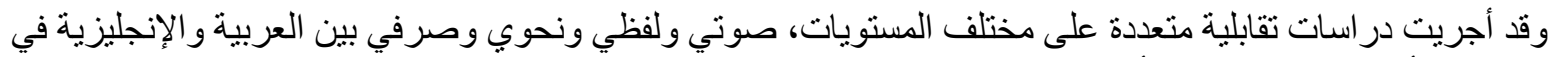

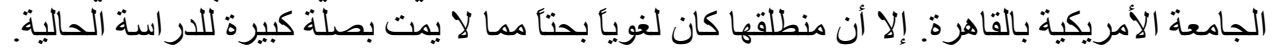

و هذه الحالة تتطبق كذلك على اللغة الإندونيسية، حيث أنه لا توجد در اسة جادة بينها وبين العربية رغم وجود بهد علاقة وطيدة

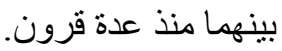

\section{أولا: التقابل بين الأصوات العربية والإندونيسية}

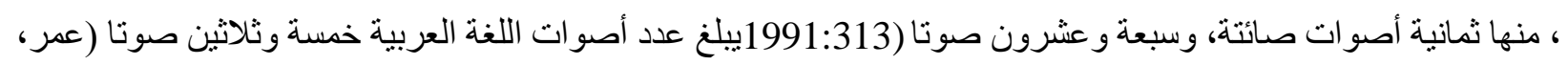
، و الباقية الخامسة (Vowels) صامتا، بينما يبلغ أصوات اللغـة الإندونيسية واحدا وثلاثين صوتا، ستة منها للأصو ات الصنات الصائتة و العشرون للأصوات الصامتة منهات الاصنة (Consonants).

ولكي يتضح لنا مدى الاختلاف و الائتلاف بين أصوات هاتين اللغتين يورد الباحث فيما يلي التقابل بينها

\begin{tabular}{|c|c|c|c|}
\hline بالالرمز & الأصوات الإندونيسية الإندونيسي & الريز & الأصوات العربية \\
\hline $\mathrm{i}$ & $\mathrm{i}$ & $=$ & الكسرة القصيرة \\
\hline$a$ & $\mathrm{a}$ & - & الفتحة القصيرة \\
\hline $\mathrm{u}$ & $\mathrm{u}$ & 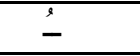 & الضمة القصيرة \\
\hline$: \mathrm{i}$ & لا يوجد & -يْْ & الكسرة الطويلة \\
\hline$: a$ & لا يوجد & $I_{-}$ & الفتحة الطويلة \\
\hline$: \mathrm{u}$ & لا يوجد & g & الضمة الطويلة \\
\hline $\mathrm{W}$ & $\mathrm{W}$ & 9 & الو او \\
\hline $\mathrm{J}$ & $\mathrm{y}$ & ي & الياء \\
\hline
\end{tabular}




\begin{tabular}{|c|c|c|c|}
\hline$\varphi$ & لا يوجد & 4 & الهمزة \\
\hline $\mathrm{b}$ & $\mathrm{b}$ & ب ب & الباء \\
\hline$t$ & $\mathrm{t}$ & $ت$ & التاء \\
\hline$\theta$ & لا يوجد & $\dot{H}$ & الثاء \\
\hline $\mathrm{dz}$ & $\bar{j}$ & ج & الجيم \\
\hline $\mathbf{h}$ & لا يوجد & $\tau$ & الحاء \\
\hline $\mathrm{X}$ & $\mathrm{kh}$ & $\dot{\tau}$ & الخاء \\
\hline $\mathrm{d}$ & $\mathrm{d}$ & د & الدال \\
\hline dh & لا يوجد & $j$ & الذال \\
\hline$r$ & $r$ & 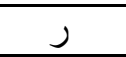 & الر اء \\
\hline $\mathrm{Z}$ & $\mathrm{Z}$ & j & الزاي \\
\hline $\mathrm{s}$ & $\mathrm{s}$ & س & السين \\
\hline$\check{\mathbf{s}}$ & sy & ش & الشين \\
\hline ș & لا يوجد & ص & الصـاد \\
\hline d & لا يوجد & ض & الضـاد \\
\hline$\underline{t}$ & لا يوجد & b & الطاء \\
\hline$z$ & لا يوجد & ظ & الظاء \\
\hline$\square$ & لا يوجد & $\varepsilon$ & العين \\
\hline gh & لا يوجد & $\dot{\varepsilon}$ & الغين \\
\hline $\mathrm{f}$ & $\mathrm{f}$ & ف & الفاء \\
\hline$q$ & $q$ & ق & القاف \\
\hline $\mathrm{k}$ & $\mathrm{k}$ & 5 & الكاف \\
\hline 1 & 1 & J & اللام المرققة \\
\hline $\mathbf{1} \square$ & 1 & J & اللام المفخمة \\
\hline $\mathrm{m}$ & $\mathrm{m}$ & 5 & الميم \\
\hline $\mathrm{n}$ & $\mathrm{n}$ & ن & النون \\
\hline $\mathrm{h}$ & $\mathrm{h}$ & هـ & الهاء \\
\hline ts & $\mathrm{c}$ & لا يوجد & لا يوجد \\
\hline $\mathrm{e}$ & $\mathrm{e}$ & لا يوجد & لا يوجد \\
\hline $\mathrm{O}$ & $\mathrm{O}$ & لا يوجد & لا يوجد \\
\hline $\mathrm{p}$ & $\mathrm{p}$ & لا يوجد & لا يوجد \\
\hline$\tilde{\mathbf{n}}$ & ny & لا يوجد & لا يوجد \\
\hline$n$ & ng & لا يوجد & لا يوجد \\
\hline $\mathrm{V}$ & $\mathrm{V}$ & لا يوجد & لا يوجد \\
\hline
\end{tabular}

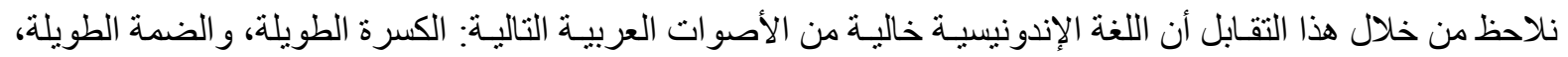

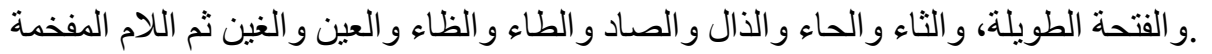

و هذه الأصو ات إذا نطقها المتعلم الإندونيسي المبتدي، تحولت إلى أصوات قريبـة الثبـه بينهما في المخرج أو الصفة.

و على الرغم من كون الأصوات العربيـة الفصحى أكثر عددا من الأصوات الإندونيسيـة، إلا أنها خالية من الأصوات الإندونيسية الناليةe, o, ts, p, ñ, n, v. ( الأندانية 2001: 62)

و أما عند حازم علي .(1991:301) ، وستة عند أحمد مختار عمر(164:1990وأنواع المقاطع الصوتية العربية خمسة (أنيس، كمال الدين فهي 


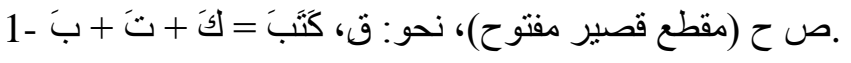

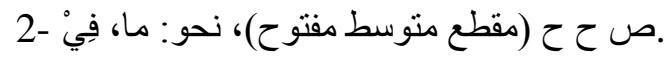

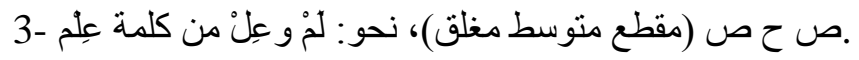

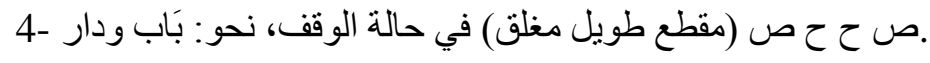

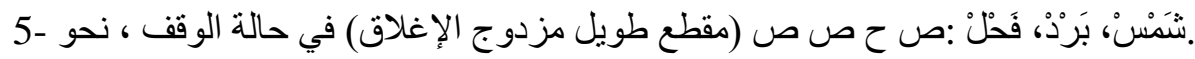

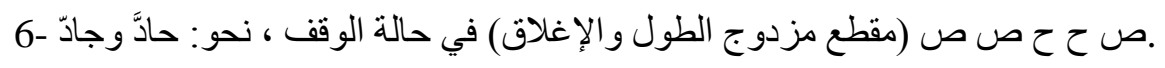

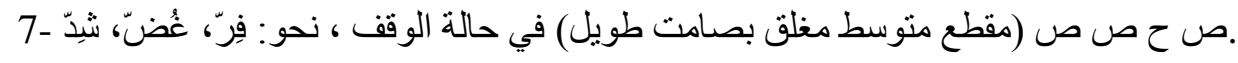

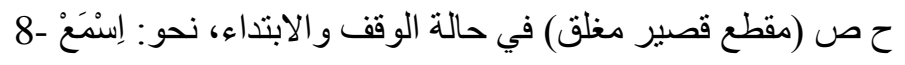

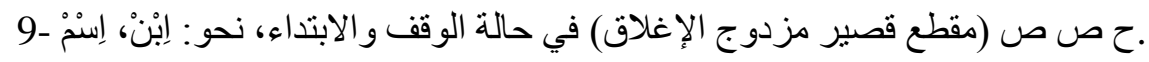

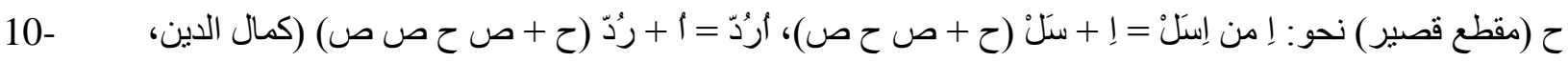
87:2002).

:وتتكون المقاطع الصوتية في الإندونيسية من احدى عشر نو عا، وهي كالتالي:

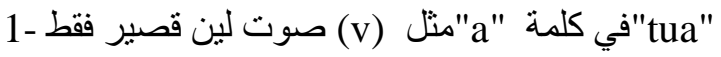

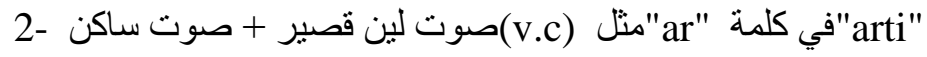

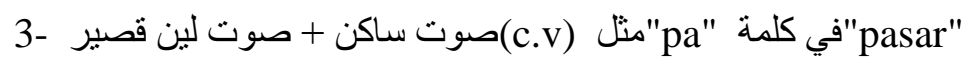

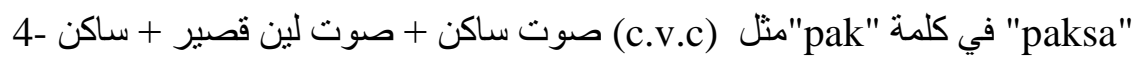

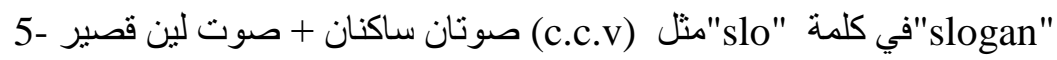

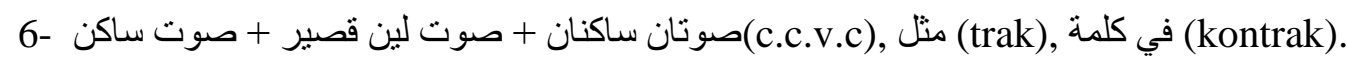

7- صوت ساكن + صوت لين قصير + صوتان ساكنان (c.v.c.c) في كلمة "tekstil"

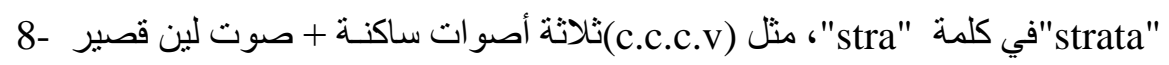

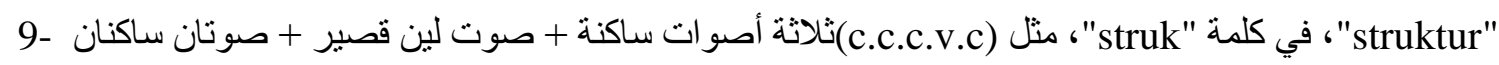

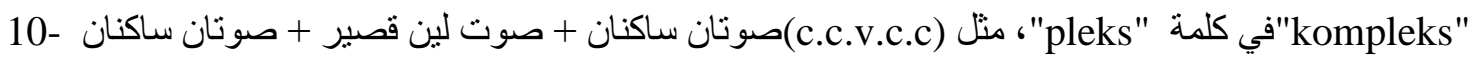

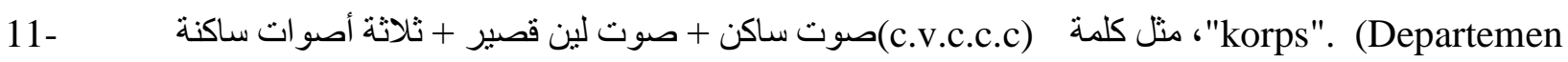

Pendidikan dan Kebudayaan RI, 1992:66-67; Keraf, 1991:223-224).

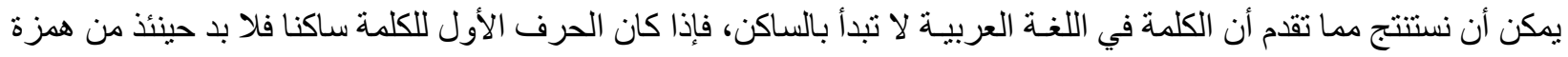

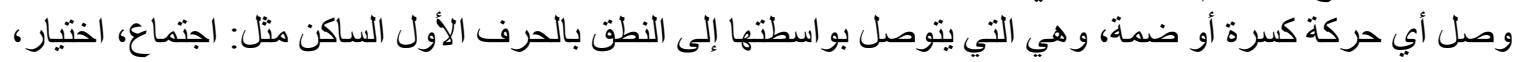

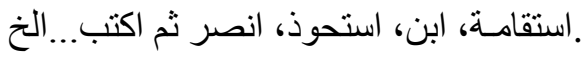

و وأما اللغة الإندونيسية ففيها كلمات كثيرة تبدأ بالساكن، أي بصوت صامت دون وجود صائت بعده.

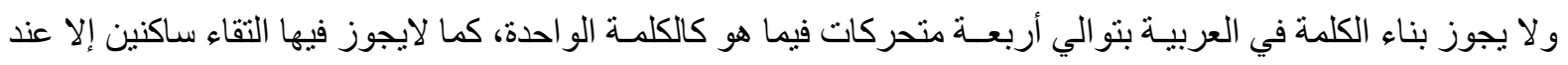

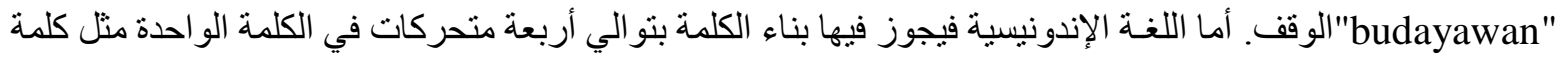

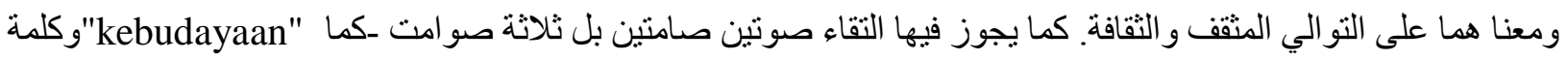
بينا آنفا في الدقاطع الصوتية.

هذه هي بعض جو انب الاختلاف بين الأصوات العربيـة والإندونيسية، وهناك اختلافات أخرى لايتسع المجال لذكر ها هنا

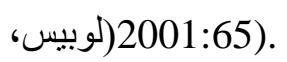


ثانيا: التقابل بين المفردات العربية والإندونيسية

ت تنقسم مفردات اللغـة الإندونيسية من حيث أصولها إلى الأقسام التالية:

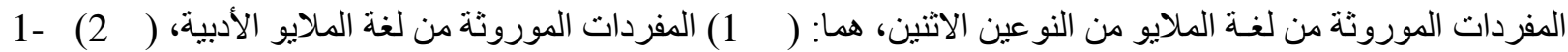

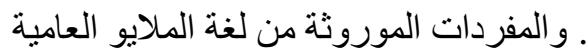

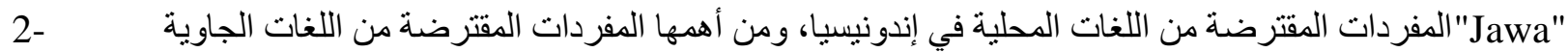

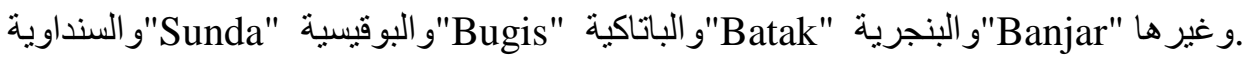

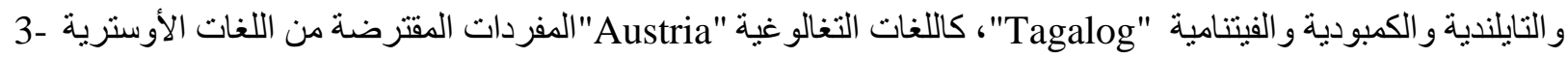

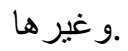

المفردات المقتر لـة من اللغات الأجنية، من أهمها اللغات العربيـة و الفارسية و الهندية و الصينية و الإنجليزية والهولنديـة 2001: 57).

: أما مفردات اللغـة العربية فتنقسم من حيث أصولها إلى الأقسام التالية

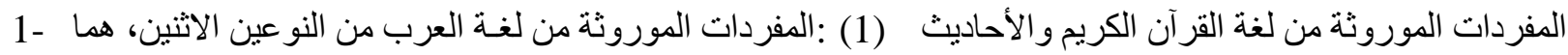

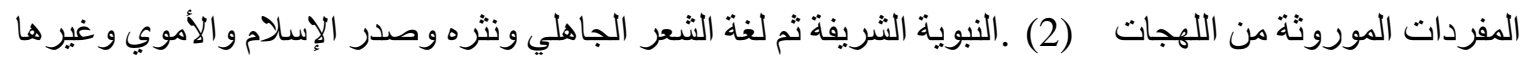
العربية القديمة و الحديثة.

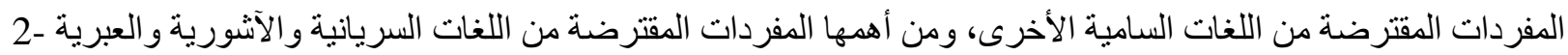
و وغيرها.

3- المفردات المقترضة من اللغات الهجاورة، كاللغات الفارسية والحبثية و البربرية و الإغريقية واللاتينية و غيرها

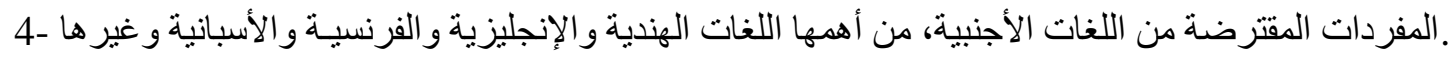

تدل على الأخ الصغير للأب و الأخ الصغير للأم، "paman"أما عن ظاهرة الفرق في المفردات فنجد في الإندونيسية كلمة

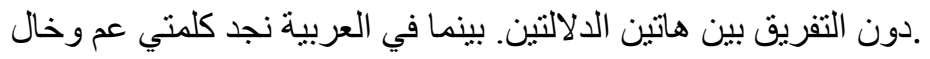

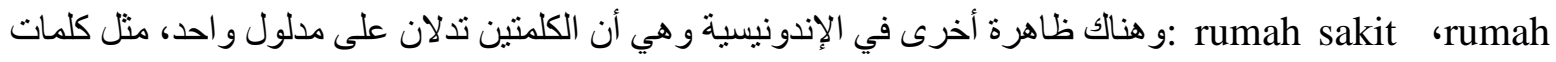
makan ،tata tertib ،cendra mata ،buku tulis 'kaca mata 'selamat datang 'selamat tinggal 'makan

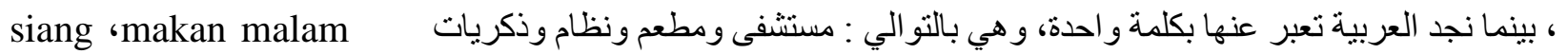
وكر اسة ونظارة ومرحبا ووداعا و غداء ثم عَثَاء.

ثالثا : التقابل بين التصريف العربي والإندونيسي

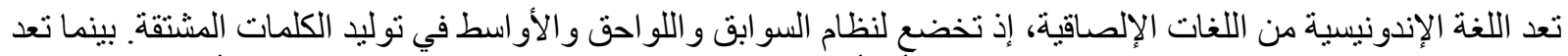

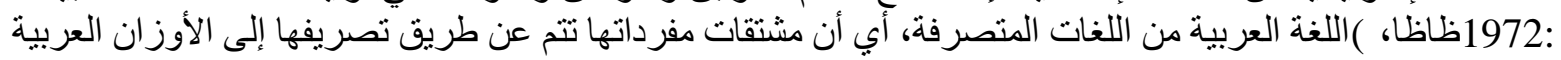
110-111).

Ahmad sedang menulis pelajaran 'Fatimah sedang menulis pelajaran, sedang menulis pelajaran Ahmad dan Fatimah sedang menulis pelajaran Para mahasiswa.

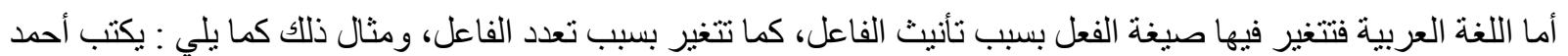

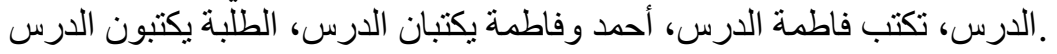

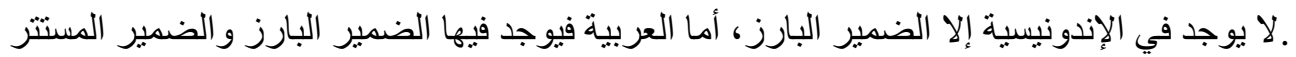


و هنالك أمر آخر يجب التركيز عليه أثناء تعلم أو تعليم الإندونيسيين اللغة العربية هو أن في العربية إفر ادا وتثثية وجمعا. أما في

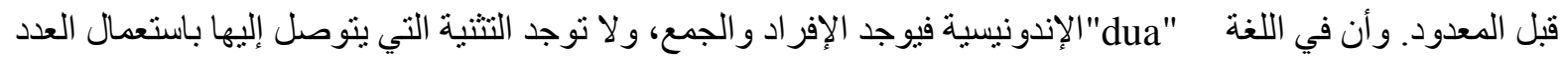

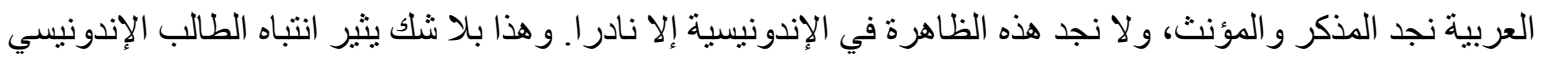

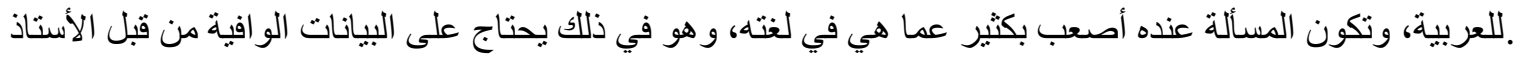

رابعا : التقابل بين التراكيب العربية والإندونيسية

القاعدة الثابتة في التركيب الفعلي في الإندونيسية تقول بأن يسبق الفاعل الفعل، ثم يأتي المفعول بعدهما، و لا يصح أن بتقدم Ahmad menulis surat

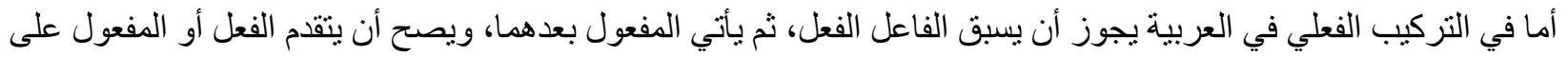

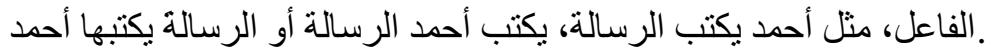

و هنالك فرق ملحوظ بين العربية و الإندونيسية في هذا النوع من التركيب، ذللك أن العربية لغة معربة بعكس اللغة الإندونيسية

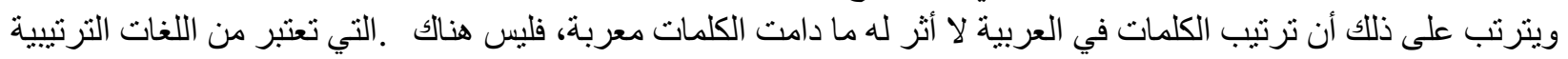

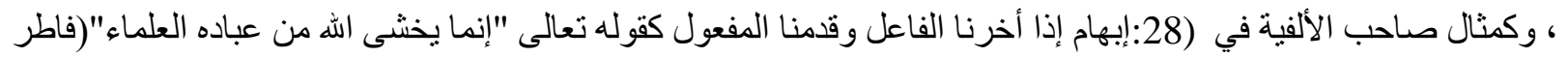
32:1992).

أما في الإندونيسية فإن ترتيب الكلمات وموقع كل كلمة هما اللذان يحددان معنى الجملة أو التركيب لكونها من اللغات الترتيبية .

(Departemen

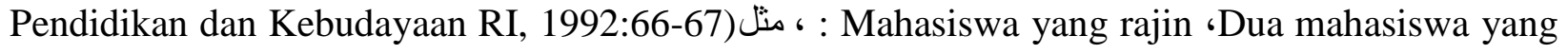
rajin ‘Beberapa mahasiswa yang rajin.

أما تركيب الصفة و الموصوف في العربية نجد أن الصفة يجب أن تتطابق مع الموصوف في التذكير و التأنيث وكذللك في الإفر اد . الطالب المجتهد، الطالبة المجتهدة، الطالبان المجتهدان، الطلاب المجتهدون : والتثنية والجمع، مثال ذلك كما يلي فئي

هناك تثابه بين اللغة العربية والإندونيسية، ويظهر ذللك بأنه يتم التركيب الإضافي في كلتيهما بوضع المضافأو لاويأتي بعده

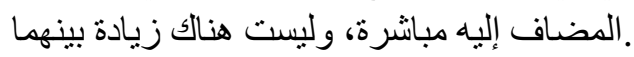

وفي العدد و المعدود يأتي العدد في هاتين .يأتي الظرف و الحال بعد الفعل في الجملة الإندونيسية، وكذلك في الجملة العربية

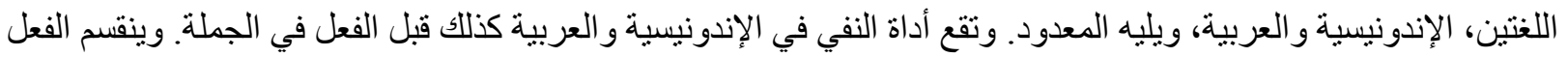

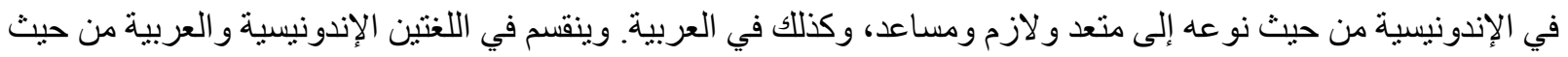
ألى زمنه إلى ماض وحال و استقبال

خاتمة

إن هذا الدرس بحث وصفي تقابلي مبسط بين اللغتين العربية والإندونيسية، إذ أنه يقابل بين مستوياتهما الصوتية و المعجمية

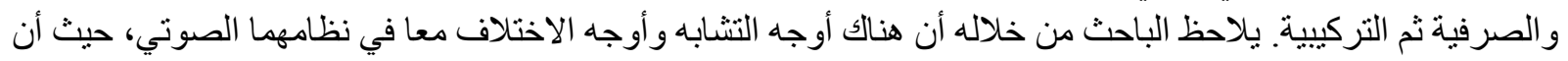

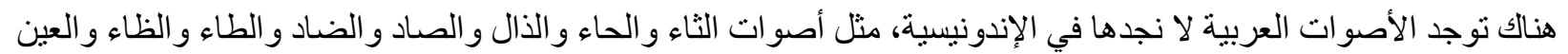

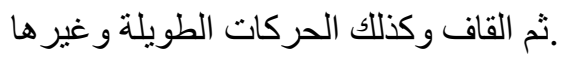

و هناك أيضا اختلاف في نظام المعج، حيث هنالك معنى تعبر عنه العربية بكلمة واحدة، بينما نجد الإندونيسية تعبر عنه

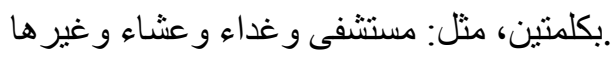

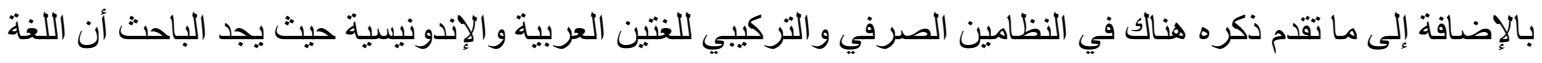

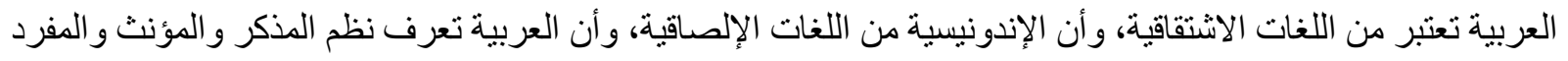
و المثنى و الجمع بخلاف اللغة الإندونيسية. 


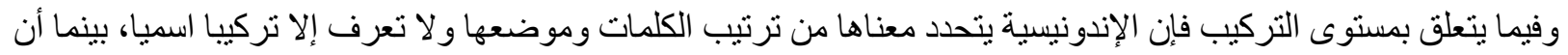

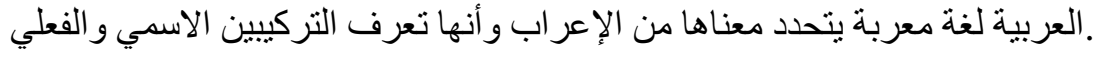

إن ناطق اللغة الإندونيسية لم يتعود على النطق بهذه الظواهر اللغوية أبي الأوجه الاختلاف بين اللغتين الإندونيسية والعربية.

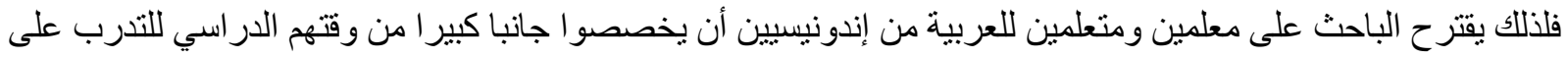

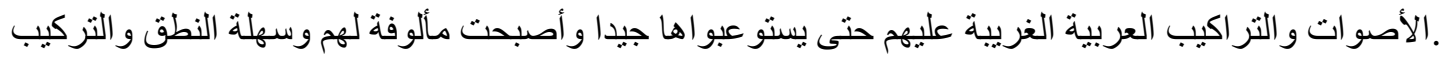

\section{المراجع}

القاهرة: الناشر مكتبة الأنجلو المصرية .الاصوات اللغوية .1990.أنيس، إبراهيم.

القاهرة: الناشر عالم الكتب .دراسة الصوت اللغوي .1991 ـعمر، أحمد مختار.

، أطروحة لنيل درجة الدكتور اه من كلية (اللغة العربية وتأثبرها في اللغة الإندونبيسية (در/سة معجمية .2001 لوبيس، توركيس الآداب و العلوم الإنسانية. نوقشت: جامعة الإندونة محمد الخامس الرباط.

القاهرة: الناشر مكتبة الآداب .ظواهر لغوية جدبية في اللغة العربية .2002 ـكمال الدين، حازم علي

القاهرة: دار الفكر العربي .اللسان والإنسان مدخل إلى معرفة اللغة .1972 ـظاظا، حسن.

إيسيسكو: منشور ات بعليم اللغة اتصاليا بين المناهج والاستر/تيجيات .2006 ـطعيمة، رشدي أحمد ومحمود كامل الناقة المنظمة الإسلامية للتربية و العلوم و الثقافة الرباط ومئاط

القاهرة: الناثر مكتبة الآداب .أصوات اللغة العربية .1994 ـخلف، عادل. 